\title{
Pharmacological investigation of Areca catechu extracts for evaluation of learning, memory and behavior in rats
}

\author{
*Madhusudan Joshi, Kavita Gaonkar, Sneha Mangoankar, Sneha Satarkar \\ Department of Pharmacology, Faculty of Pharmacy, Goa College of Pharmacy, Panaji Goa-403001, India
}

\begin{abstract}
Areca catechu Linn is one of the stimulant masticatory crude materials of Indian system of medicine. The present study was done to evaluate the effect of Areca catechu Linn extract on learning and memory in rats using radial arm maze. The extract used for study was of two different types of Areca catechu namely, wet and dried Areca catechu. Three groups of rats each consisting of seven animals were used for the purpose. Test groups were given $500 \mathrm{mg} / \mathrm{kg} \mathrm{p.o} \mathrm{of}$ wet Areca catechu extract and dried Areca catechu extract respectively. It was observed that wet Areca catechu extract showed greater increase in spatial memory and learning in comparison to the control group of rats. Hence increase in spatial memory could be because of higher amount of arecoline present in wet Areca catechu extract.
\end{abstract}

Key Words: Areca catechu, Radial arm maze, Memory, Learning.

\section{INTRODUCTION}

Throughout the world, plants and herbs have had a unique place in all the civilizations. India is one of the largest populated countries in the world and it has eight different geographical zones. In rural India, the consumption of betel nut (Areca nut) with betel leaf is a common practice. Areca nut contains several medicinally active substances. Areca nuts are consumed in two different forms that are in wet and dry form. The wet form is an undried form of ripened nuts whereas the dried Areca nuts are sundried ripened betel nuts.

Learning may be defined as the ability to alter behaviour on the basis of experience. Whereas 'Memory' is the ability of an individual to record sensory stimuli; events, information, etc. retain them over short or long periods of time and recall the same at a later date when needed. Memory can be divided into two basic types or stages: Short-term and Long-term memory (Guyton, 1991).

\footnotetext{
*Corresponding Author:

Madhusudan Joshi

Department of Pharmacology

Faculty of Pharmacy, Goa College of Pharmacy

$18^{\text {th }}$ June Road, Panaji Goa-403001, India

E-mail: joshimadhusudan@rediffmail.com

Contact No.: 09423059036
}

Areca nut (Areca catechu) popularly known as "betel nut", is one of the oldest known masticatories amongst Asia (Trease and Evan, 2009). It was cited for its various medicinal properties, specially antibacterial and antiviral activity (Reena et al., 2009; Lalithkumari and Sirsi, 1965; Sastry, 2005). Seeds of Areca nut contain catechin, tannins (15\%), Gallic acid fat, gum and alkaloids like arecoline (0.07\%), arecaine $(1 \%)$. Arecaidine and guvacoline, guvacine and choline are present in trace amount. Among these, arecoline is the most important alkaloid (Reena et al., 2009; Nadkarni, 1976; Dhinegra and Sharma, 2006). It acts as agonist on muscarinic receptor. Areca catechu extract has Central Nervous System stimulant effect which is mostly due to presence of these alkaloids (Dhinegra and Sharma, 2006; Azeezl et al., 2007; Aromdee et al., 2003). Amount of alkaloid present in Areca nut differs depending on stage of development of the nut. In the present study two different types of Areca catechu extract was tested for evaluation of their effects on Central Nervous System activity i.e. learning and memory in rat. 


\section{MATERIALS AND METHODS}

\section{Ethics}

This project work was approved by Institutional Animal Ethics Committee (IAEC Ref No.: GCP/IAEC/10/03/PG RESEARCH).

\section{Preparation of test solution}

Samples of two different types of areca nut (Areca catechu) were obtained from a local market and used in this study. The sample was crushed and nut portion was collected. This was further crushed to get coarse powder with help of mortar and pestle. The powder was weighed and soaked in the methanol in a ratio of $1 \mathrm{gm}$ in $2.5 \mathrm{ml}$. It was covered with aluminum foil and kept overnight. After soaking overnight, sample was again stirred and filtered through Whatmann filter paper. Filtrate is then collected and evaporated till dryness. Red colored flakes were obtained which were crushed and powdered. Weight of extract was noted. $1 \mathrm{gm}$ of Areca catechu extract was weighed and transfer into $10 \mathrm{ml}$ volumetric flask. Extract was dissolved in distilled water and volume was made up to $10 \mathrm{ml}$. Suspension of this extract $(100 \mathrm{mg} / \mathrm{ml})$ was was administered orally. Portion of this was used for quantification of Arecoline, by dissolving in excess of $0.02 \mathrm{~N}$ Sulfuric acid and titrating against $0.02 \mathrm{~N}$ Sodium hydroxide using Methyl red as indicator (Vogel et al, 2002). A reverse phase high pressure liquid chromatography was developed to determine presence of Arecoline in areca nut.

\section{Equipments}

Beaker, volumetric flasks, pipette, separating funnel, funnel, glass rod, Whatmann filter paper, litmus paper, HPLC (Knauer Ltd.), pH meter (Toshcon Ltd.), Injection syringe.

\section{Material}

Wet Areca catechu extract, dried Areca catechu extract, $0.1 \mathrm{~N}$ Hydrochloric acid, Methanol, Chloroform, $1 \mathrm{~N}$ Ammonium hydroxide. The column, Thermofacia scientific $(250 \times 4.6 \mathrm{~cm})$ used were $\mathrm{C}-18$ reverse phase columns, the mobile phase was a Phosphate buffer of $\mathrm{pH} 5.5$, and the UV detectors were set at $216 \mathrm{~nm}$. The chromatogram thus obtained was compared with that of a standard Arecoline samples (Chu, 1995).

\section{Experimental Animals}

Albino rats of Wistar strain (180-200g) were selected for the experiments. Animals were maintained as per CPCSEA guidelines. The bedding material of the cages was changed thrice in a week using rice husk. The animals were well acclimatized for one week to the laboratory conditions before starting the experiment.

\section{Groups}

To measure effect on Central nervous system 21 rats were used. They were divided into three groups randomly with each group containing 7 animals.

Group 1: served as a control.

Group 2: received $500 \mathrm{mg} / \mathrm{kg}$ of dried Areca catechu extract orally $60 \mathrm{~min}$. prior to the experiment.

Group 3: received $500 \mathrm{mg} / \mathrm{kg}$ of wet Areca catechu extract orally $60 \mathrm{~min}$. prior to the experiment.

\section{Effect on learning and memory}

To test effect of test compound on learning and memory Radial Arm Maze model was used according to Dar and Khatoon (2000). Animals were kept hungry for overnight and then placed individividualy on the radial arm apparatus. Corns were kept in one of the arm. The experiment was followed using the SOP (Standard Operating Procedure). The test compound was administered orally, one hour prior to experimentation. The treated and the control group of rats were trained for a period of three weeks (21 days) to search for the food and time taken to reach the food was noted down. At the end of three weeks the effect of the test compound on learning was tested. Training was discontinued for the next seven days, but the administration of the test compound was continued. Effect of drug on memory was tested by keeping gap of 7 days and on $8^{\text {th }}$ day rechecking if rats remember that food is kept in one of the arm.

\section{Effect on locomotor activity}

The instrument was operated using the SOP (Standard Operating Procedure). Rats were pretested on the apparatus. Only those rats which had demonstrated their ability to remain on the revolving rod for at least 1 minute were used for the test. The drug was given orally, one hour prior to experimentation. The treated and the control group of rats were placed on the rotating rod and the fall off time was noted. Activity was noted after 1, 2, 4, 6 
Table 1: Effect of Areca catechu extracts on learning and memory using Radial Arm Maze.

\begin{tabular}{lccc}
\hline \multirow{2}{*}{ Treatment $(\mathbf{m g} / \mathbf{k g})$} & \multicolumn{3}{c}{ Latency to find feed (min) } \\
\cline { 2 - 4 } & Day one of training & $\begin{array}{c}\text { After twenty one } \\
\text { days of training }\end{array}$ & After seven days of gap \\
\hline Control & $4.249 \pm 0.244$ & $2.293 \pm 0.356$ & $3.857 \pm 0.340$ \\
Dried Areca catechu Extract $(500 \mathrm{mg} / \mathrm{kg} \mathrm{p.o)}$ & $3.851 \pm 0.280$ & $0.890 \pm 0.129^{* * *}$ & $1.136 \pm 0.197^{* *}$ \\
Wet Areca catechu extract $(500 \mathrm{mg} / \mathrm{kg} \mathrm{p.o)}$ & $3.746 \pm 0.181$ & $0.304 \pm 0.027^{* * *}$ & $0.470 \pm 0.119^{* *}$ \\
\hline
\end{tabular}

Values are expressed as mean \pm SEM $(n=7){ }^{* *} \mathrm{P}<0.01,{ }^{* * *} \mathrm{P}<0.001$ vs. Control.

Table 2: Effect of Areca catechu extract on locomotor activity using Rotamex Instrument (day one).

\begin{tabular}{lcccccc}
\hline \multirow{2}{*}{\multicolumn{1}{c}{ Treatment (mg/kg) }} & \multicolumn{5}{c}{ Time of fall (sec) } \\
\cline { 2 - 6 } \multicolumn{1}{c}{ Control } & $168.94 \pm 23.73$ & $170.50 \pm 22.89$ & $171.93 \pm 24.24$ & $170.50 \pm 23.65$ & $170.50 \pm 23.65$ \\
Dried Areca catechu extract $(500 \mathrm{mg} / \mathrm{kg})$ & $145.84 \pm 25.66$ & $114.26 \pm 12.89^{*}$ & $129.39 \pm 12.81$ & $122.81 \pm 20.32$ & $125.89 \pm 29.27$ \\
Wet Areca catechu extract $(500 \mathrm{mg} / \mathrm{kg})$ & $50.71 \pm 20.37^{* *}$ & $62.78 \pm 23.3^{* *}$ & $129.33 \pm 12.20$ & $120.03 \pm 15.24$ & $156.50 \pm 39.81$ \\
\hline
\end{tabular}

and 24 hours. The above procedure was followed to obtain the seventh and fourteenth day readings.

\section{Statistics}

Data were analyzed by Prism Graph Pad® software (version 3.10) and presented as mean \pm S.E.M. values. The statistical tests used were one-way analysis of variance (ANOVA) followed by Dunnet's test. A probability level of 0.05 or less was considered statistically significant. No untoward observations were seen in the behaviour of the animals when observed for first 24 hrs. No gross behavioural changes and mortality were observed for 14 days after single drug administration.

\section{RESULTS AND DISCUSSION}

It was noted that after continuous treatment with extract, group three which received wet Areca catechu extract showed greater reduction in latency to find feed, which was of statistical significance $(\mathrm{P}<0.001)$. Latency to reach feed recorded for control group of rats using Radial arm maze was found to be $4.249 \pm 0.244$ minutes on day one and $2.293 \pm 0.356$ minutes after 21 days.

Latency of $3.851 \pm 0.280$ minutes on day one and $0.890 \pm 0.129$ minutes $(\mathrm{P}<0.001)$ on $21^{\text {st }}$ day for group treated with dried Areca catechu extract was found. Group treated with wet Areca catechu extract showed latency of $3.746 \pm 0.181$ minutes on day one, $0.304 \pm 0.027$ minutes $(\mathrm{P}<0.001)$ on $21^{\text {st }}$ day.
From the quantitative estimation and HPLC separation of both the extracts it was seen that Wet Areca catechu extract contains higher amount of alkaloid than dried Areca catechu extract. Further quantitative analysis of Areca catechu extract was done by titrimetric method and it revealed that amount of arecoline present in wet Areca catechu extract was $0.2 \%$ and amount of arecoline present in dried Areca catechu extract was $0.16 \%$. This indicates that amount of arecoline present in wet Areca catechu extract was more than that of dried Areca catechu extract, thus it could be attributed to the effect on CNS. Areca catechu extract produces a significant reduction in the latency to find feed when given continuously for 21 days in the radial arm maze. This reveals that it improved the ability to retrieve information and therefore strengthens explicit memory. Effect on memory indicates that in comparison with dried Areca catechu extract, wet Areca catechu extract showed significant improvement in memory. Learning is the process of acquiring knowledge, information and skills. Memory is retrieval of the information acquired earlier. In the present study, an attempt was made to access the effect of different type of Areca catechu extract on learning and Memory. Healthy rats were subjected to radial arm maze test for the purpose. The latency to find feed was the criteria used to access learning as well as spatial memory of rats. Animals were trained to search for feed. It was noted that after continuous treatment with extract, group three which received wet Areca catechu extract 
Table 3: Effect of Areca catechu extract on locomotor activity using Rotamex Instrument (day seven).

\begin{tabular}{lcccccc}
\hline \multirow{2}{*}{\multicolumn{1}{c}{ Treatment (mg/kg) }} & \multicolumn{5}{c}{ Day seven- Time of fall (sec) } \\
\cline { 2 - 6 } & $\mathbf{1 h r}$ & $\mathbf{2 h r}$ & $\mathbf{4 h \mathbf { h }}$ & $\mathbf{6 h r}$ & $\mathbf{2 4 h \mathbf { h r }}$ \\
\hline Control & $127.26 \pm 20.68$ & $131.26 \pm 21.68$ & $130.22 \pm 21.44$ & $130.20 \pm 21.64$ & $127.26 \pm 20.68$ \\
Dried Areca catechu extract $(500 \mathrm{mg} / \mathrm{kg})$ & $168.81 \pm 18.23$ & $177.77 \pm 26.87$ & $175.03 \pm 29.02$ & $152.72 \pm 22.34$ & $137.80 \pm 22.05$ \\
Wet Areca catechu extract $(500 \mathrm{mg} / \mathrm{kg})$ & $59.77 \pm 13.03^{*}$ & $118.76 \pm 24.37$ & $121.71 \pm 28.68$ & $112.91 \pm 22.57$ & $116.69 \pm 23.87$ \\
\hline
\end{tabular}

Values are expressed as mean \pm SEM $(\mathrm{n}=7){ }^{*} \mathrm{P}<0.05,{ }^{* *} \mathrm{P}<0.01$ vs. Control.

Table 4: Effect of Areca catechu extract on locomotor activity using Rotamex Instrument (day fourteen).

\begin{tabular}{lccccc}
\hline Treatment (mg/kg) & \multicolumn{5}{c}{ Day fourteenth- Time of fall (sec) } \\
\cline { 2 - 6 } & $\mathbf{1 h r}$ & $\mathbf{2 h r}$ & $\mathbf{4 h r}$ & $\mathbf{6 h r}$ & $\mathbf{2 4 h \mathbf { h r }}$ \\
\hline Control & $132.97 \pm 21.70$ & $132.97 \pm 21.70$ & $140.13 \pm 11.09$ & $132.97 \pm 21.70$ & $140.13 \pm 11.09$ \\
Dried Areca catechu extract $(500 \mathrm{mg} / \mathrm{kg})$ & $167.20 \pm 28.52$ & $153.74 \pm 16.28$ & $158.96 \pm 21.01$ & $162.51 \pm 16.34$ & $151.26 \pm 14.99$ \\
Wet Areca catechu extract $(500 \mathrm{mg} / \mathrm{kg})$ & $99.171 \pm 8.34$ & $118.13 \pm 13.99$ & $135.63 \pm 12.76$ & $148.37 \pm 24.51$ & $179.29 \pm 24.45$ \\
\hline
\end{tabular}

Doses were given per kg p.o for 28 days.

showed greater reduction in latency to find feed, which was of statistical significance $(\mathrm{P}<0.001)$. Results of radial arm experiment are given in table 1. Latency to reach feed recorded for control group of rats using Radial arm maze was found to be $4.249 \pm 0.244$ minutes on day one and $2.293 \pm 0.356$ minutes after 21 days. A group treated with dried Areca catechu extract showed latency of $3.851 \pm 0.280$ minutes on day one and $0.890 \pm 0.129$ minutes $(\mathrm{P}<0.001)$ on $21^{\text {st }}$ day. Group treated with wet Areca catechu extract showed latency of $3.746 \pm 0.181$ minutes on day one, $0.304 \pm 0.027$ minutes $(\mathrm{P}<0.001)$ on $21^{\text {st }}$ day. Effect on memory indicates that in comparison with dried Areca catechu extract, wet Areca catechu extract showed significant improvement in memory. The latency to find feed was noted as $1.136 \pm 0.197$ minutes $(\mathrm{P}<0.01)$ in case of dried Areca catech $u$ and $0.470 \pm 0.119$ minutes $(\mathrm{P}<0.01)$ in comparison to control. Preliminary phytochemical screening of Areca catechu extract had shown that amount of arecoline present in wet Areca catechu was higher than that of dried Areca catechu extract. Therefore increase in spatial memory could be because of higher amount of arecoline present in wet Areca catechu extract.

\section{CONCLUSION}

It was demonstrated by animal study that both wet Areca catechu and dried Areca catechu extract show increase in learning and memory on continuous administration without much impairment of neuromuscular tone. It was reported that compared to dried Areca catechu extract treated rats, the wet Areca catechu extract treated rats showed faster learning and higher memory effect. Thus study clearly indicates that Areca catechu extract increases learning and memory. However, further intensive studies are necessary to confirm and extend these results.

\section{REFERENCES}

Aromdee, C., Panuwougse, S., Anorach, R. and Vorarat, S. (2003). A High Pressure Liquid Chromatographic Method for the Determination of Arecoline in Areca nut, Thai. J. Pharm. Sci., 27(1-2): 41-47.

Azeez, S., Amudhan, S., Adiga, S., Rao, N., Laxminarayana, A. (2007). Wound Healing Profile of Areca catechu Extracts on Different Wound Models in Wistar Rats. Kuwait Medical Journal, 39(1): 48-52.

Chu, N.S. (1995). Sympathetic response to betel chewing. Journal of Psychoactive Drugs. 5: 183-186. DOI PMid:7562268

Dar, A. and Khatoon, S. (2000). Behavioural and biochemical studies of dichloromethane fraction from the Areca catechu nut. Pharmacol biochem. behave. 65: 1-6.

Dhinegra, D., and Sharma, A. (2006). A review on antidepressant plants, Nature products radiance. New Delhi; by National institute of science, communication and information resources. 5(2): 146-168.

Dua, J., Prasad, D.N., Tripathi, A.C., and Gupta, R. (2009). Role of traditional medicine in Neuropsychopharmacology, Asian Journal of Pharmaceutical and Clinical Research. 2(2): 42-46

Guyton, A., (1991). Textbook of Medical Physiology. $8^{\text {th }}$ edition, Prism book Pvt. Ltd., Pp. 477. 
Ingole, S.R., Rajput, S.K. and Sharma, S.D. (2008). Cognition Enhancers: Current strategies and future perspectives. CRIPS.9: 42-46.

Lalithkumari, H., and Sirsi, M. Antibacterial (1965) Antifungal activity of Areca catechu Linn., Indian Journal of Experimental Biology, 7: 66.

Nadkarni, A.K. (1976). Indian material Medica. $3^{\text {rd }}$ Ed, Mumbai; Bombay Popular Prakashan; Vol. 1.

Parle, M., Vasudevan, M. (2007). Memory Enhancing Activity of Abana: An Indian Ayurvedic Poly-herbal Formulation. Journal of Health Science. 53: 43-52. DOI

Pithuyanukul, P., Nithitanakal, S. and Bavovada, R. (2009). Hepatoprotective Potential of Extracts from Seeds of Areca catechu and Nutgalls of Quercus infectoria. Molecules, 14(12): 4987-5000. DOI PMid:20032872

Reena, R., Authikat, N., Michael, A. (2009). Study on the Areca nut for its antimicrobial properties. Pharmacognosy. 1(1): 42-45.
Sastry, J.L.N. (2005). Dravyaguna Vijnana - Volume 2: Fundamental Principles of Pharmaco-therapeutics in Ayurveda, Varanasi, Chaukhambha Orientalia, India.

Sharma, K., Arora, V., Rana, A.C. and Bhatnagar, M. (2009). Anxiolytic effect of convolvulus pluricaulis choisy petals on elevated plus maze model of anxiety in mice. Journal of Herbal Medicine and Toxicology. 3(1): 41-46.

Trease and Evan, W.C. (2009). Pharmacognosy. $15^{\text {th }}$ edition, Elsevier, Noida.

Gogte, V.V.M. (2005). Ayurvedic pharmacology and therapeutic uses of medicinal plants (Dravyagunavignyan), Mumbai; Bhartiy Vidhya Bhavan. Pp. 672.

Vogel, H.G., Schölkens B.A., Sandow, J., Muller, G., Vogel, W.F. (2002). Drug Discovery and Evaluation- Pharmacological Assays. $2^{\text {nd }}$ Edition, Springer-Verlag Berlin Heidelberg, Pp. 398, 434-435, 443-444, 630-631, 696.

Wallis, T.E. (2005). Textbook of Pharmacognosy, $5^{\text {th }}$ edition, New Delhi, CBS Publishers and distributor. 